\title{
Research on the Dilemma and Countermeasures of Chinese College Students' Entrepreneurship
}

\author{
Jie Hou ${ }^{1, a}$ \\ 'Shenzhen Polytechnic, Xili Lake, Nanshan District, Shenzhen, Guangdong Province, P.R.China \\ a595131976@qq.com \\ *JieHou
}

Keywords: Entrepreneurship, Entrepreneurship education, Business ecosystem.

\begin{abstract}
Based on the theory of organizational ecology, this paper studied the difficulties faced by college entrepreneurs, which include financing, social network, marketing, management difficulties, etc., and pointed out that universities should promote the legalization strategy effectively to improve the survival rate of students' new venture, such as building niche company nurturing platform, promoting entrepreneurship competition, entrepreneurship competition guide, establishing entrepreneurial oriented credit system for students.
\end{abstract}

\section{Introduction}

Compared to company personnel, college students lack social network and working experience, so they are not the dominant groups of entrepreneurships. But on the other hand, college students have strong entrepreneurial awareness, innovative spirit, little sunk cost, and are faced with tremendous employment pressure. Under the encouragement of China's innovation and entrepreneurship policy, the number of registered college entrepreneur had reached 615 thousand in 2016, and made their entrepreneurial dilemma a prominent problem.

Many scholars have conducted questionnaire surveys on college students' entrepreneurial difficulties, such as financing difficulties, market development difficulties, huge risk, lack of social relations, business opportunities, management capacity, etc. The entrepreneurial dilemma was so multifarious and it was impossible for college to find countermeasures for each problem. Through lens of legitimacy concept in organizational ecology theory, we found that all the college students' entrepreneurial dilemma could be induced to lack of legitimacy, and gave the countermeasures based on the organizational ecology.

\section{Theory of new ventures legitimacy}

An organization's legitimacy is the degree to which it is socially accepted [1]. As functional nodes of social and economic ecological network, new ventures have to occupy a certain niche, use social resources and provide services to society. This process must be approved by many roles in the business ecosystem, such as customers, government, financial institutions, organizations in supply chain, etc., so new venture's establishment is a social legitimation embeddedness process [2].

It is particularly important for new ventures to acquire resources through the legitimation strategy [3], Scott (2001) divided legitimacy into three dimensions: cognitive, regulative and normative legitimacy [4]. Cognitive legitimacy means the acceptance of the organization as necessary or inevitable, it will grow as well as the society become used to the new venture. Regulative legitimacy related to the degree of new venture's compliance with government laws, policies and relevant associations certifications, standards. The more they meet the regulatory requirements, the more easily they are accepted by society. Normative legitimacy is the degree to which new venture's work norms, habits, sense of worth, technology meets the social values. 


\section{Analysis of college students' entrepreneurial dilemma}

According to legitimacy theory, the success of the college student's new venture is more dependent on their legitimation strategy. Present entrepreneurship education overemphasized the innovation and uniqueness of the entrepreneurial project, but a highly innovative product needs more resources and more legitimation supports, as it will arouse strong reactions of the members in the business ecosystem, such as the non-support from government, supplier, investor, and the non-acceptance of the customers, the strong opposition of the competitors and so on, which will form a huge obstacle to legitimation[5, 6]. Therefore, innovation and uniqueness are the resource endowments of new ventures, they could bring some competitive advantage, but cannot ensure that the ventures occupy a certain niche in the business ecosystem. In addition, overemphasizing competition advantage will make new ventures suffer fierce reactions from competitors, the consumption of resources caused by competition will reduce the resource used in meeting the needs of customers, thereby reducing the legitimacy of enterprises, which is not conducive to the survival of new ventures. OfO and Mobike is a good example.

We analyzed many questionnaire surveys on college students' entrepreneurial difficulties in Beijing, Zhejiang, Hunan, etc., and find that lack of funds, difficulties in financing, lack of social relations, difficulties in market development, lack of good entrepreneurial projects and directions, lack of knowledge and management ability, human resource problems, lack of partners are the mostly mentioned difficulties, see Table 1.

Table 1. College students' entrepreneurial dilemma

\begin{tabular}{cc}
\hline College students' entrepreneurial dilemma & Data sources \\
\hline Financing difficulties & Tingying He\&Liping Zhang, 2007; Jingbao Huang, 2010; \\
& Shan Ao, 2011; Shaohua Jia, 2008; JingWang, 2011; \\
Zhongyu Yan,etc., 2013; & Tingying He\&Liping Zhang, 2007; Jingbao Huang, 2010; \\
Shaohua Jia, 2008; JingWang, 2011; & Shan Ao, 2011; Shaohua Jia, 2008; \\
\hline Lack of social relationship & Tingying He\&Liping Zhang, 2007; JingWang, 2011; \\
& Zhongyu Yan,etc., 2013; \\
\hline Marke development difficulties & Tingying He\&Liping Zhang, 2007; Shan Ao, 2011; Shaohua \\
Seeking business opportunity difficulties & Tingying He\&Liping Zhang, 2007; Shan Ao, 2011; \\
\hline Management problems & Jingbao Huang, 2010; JingWang, 2011; \\
\hline Partners and human resource problems & Jingbao Huang, 2010; \\
\hline Knowing little about policy & JingWang, 2011; Zhongyu Yan,etc., 2013;
\end{tabular}

Financing difficulties/Family opposition: Financing difficulties is the first and most important factors for college entrepreneurs. Lacking initial capital and having subsequent financing difficulties are the two main manifestations. College students have no income, their start-up funds mainly come from government, social capital and family, subsequent capital comes from small business loans, venture capital [7]. Financing difficulties is just skin-deep, the real reason is lacking cognitive legitimacy. First, no social capital support meant some college students' entrepreneurship project were believed no better than the social ones, social capital had better choices. Second, no government financial support meant some college students' entrepreneurship project didn't join or pass the government venture fund selection, it was the representation of lacking cognitive legitimacy. Besides, entrepreneurs' unfamiliarity with government venture fund policy also show that they lack regulative and normative legitimacy. Third, no family financial support partly indicated that the project was not recognized by the family, it was also a representation of lacking cognitive legitimacy.

Seeking business opportunity difficulties: According to Timmons' entrepreneurial model, business opportunity is the most important process in the starting stage, entrepreneur should spend most of their time on looking for business opportunities. Many college students had difficulties on this process because they did not know how to find and evaluate business opportunities. Besides, many theoretical entrepreneurship courses overemphasized entrepreneurship's risk, difficulty and 
failure, which made college students undervalue the opportunities [8, 9]. As these college students didn't meet the specification of entrepreneurs, it was a representation of lacking normative legitimacy.

Market development and social relationship difficulties: Market and social network are resources for a company, and the acquisition of resource is closely related to legitimacy. Aldrich \&Fiol (1994) found that many failures were attributed to the lack of market potential, but the fact was those entrepreneurs could not build a good relationship with the stakeholders, and deal with the competitive relationship[10]. One college student entrepreneur said 'a solid customer means a solid income, more customers, more wealth', which could also be an evidence of the conclusion [11]. These difficulties can be divided into lacking of regulative and normative legitimacy.

Partners and team management problems: College students had little experience in enterprise management, and the profitability, management normalization, fair treatment of employees were generally questioned, so these problems were typically caused by lacking of normative legitimacy

Knowing little about policy: Many college entrepreneurs knew little about the policies useful for their entrepreneurship, such as financial subsidies, tax incentives, personnel training, etc. Obviously, they were not working hard on regulative legitimacy.

The analysis result is shown in Fig. 1.

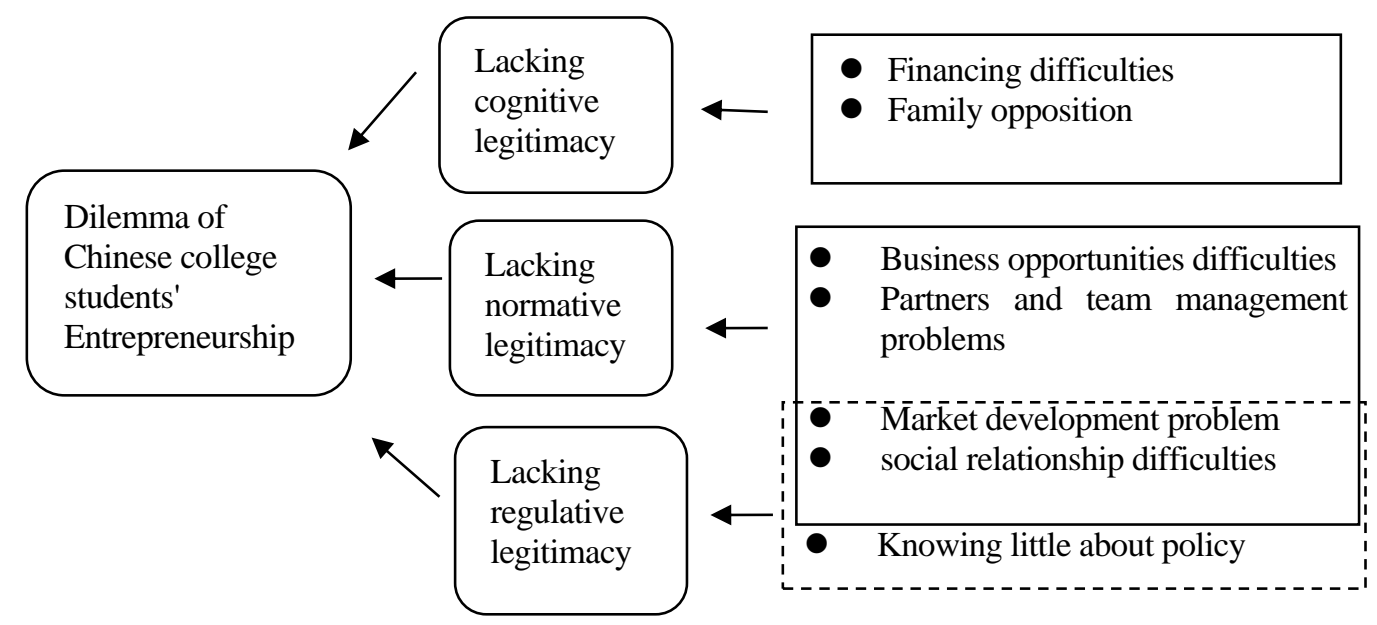

Fig. 1. The relationship between the entrepreneurship dilemma and legitimacy

\section{Countermeasures of Chinese college students' entrepreneurship}

\subsection{Building niche company nurturing platform through school-enterprise cooperation}

From the perspective of legitimacy, recognition by key stakeholders can become a very important resource, which can greatly promote the growth of enterprises [3]. Large and medium-sized enterprises, especially those enterprises who has its own business ecosystems, are the typical key stakeholders.

These key enterprises are very happy to nurture new niche companies in their business ecosystem. The more niche companies in their ecosystem, the more competitive they are. With the help of the keystone enterprises, college students' new venture can gain legitimacy more easily, such as market, social relationship, technology and finial support, people's training, etc. Besides, finding business opportunities in a niche market of certain enterprises' ecosystem is much easier than just 'daydream' in school. The student entrepreneurs provide products and services based on the keystone enterprises' existing standards, which are of great help to their regulative and normative legitimacy.

\subsection{Promoting and perfecting the entrepreneurship competition of college students}

Currently, a lot of entrepreneurship competition just focused on competition itself, ignoring the following up support. For example, Jing Gao's(2014) research showed that entrepreneurship competition greatly raised the entrepreneurial willingness of college students, but owing to the inefficiency of supporting funds and policy, students could not able to further advance their 
entrepreneurship project, entrepreneurship competition just became a show. So college entrepreneurship competition should be perfected with the whole nurturing process chain, including selection and cultivation of creativity, internship platform, and the following policy, financial, operational support.

\subsection{Establishing entrepreneurial oriented credit system for college students}

Trust is one of the basic conditions for entrepreneurs to gain legitimacy. The establishment of trust between entrepreneur and social capital is a long and complex process. The college student credit system, which mainly record students' real internship experience and comment from the responsible, co - operating company, which can make the trust building process faster and easier.

\section{Acknowledgement}

This research was financially supported by the Guangdong Province Natural Science Foundation (Grant NO. 2015A030310525)

\section{References}

[1] T. Kostova and S. Zaheer, Organizational Legitimacy under Conditions of Complexity: The Case of the Multinational Enterprise, Academy of Management Review, vol. 24, pp. 64-81, 1999.

[2] Y.L.Zhang and G.C.Du, The legitimacy paradox of entrepreneurship, China Soft Science, vol. 10, pp. 47-58, 2007.

[3] M. A. Zimmerman and G. J. Zeitz, Beyond survival: Achieving new venture growth by building legitimacy, Academy of Management Review, vol. 27, pp. 414-431, 2002.

[4] W. R. Scott, Institutions and organizations, Sage Publications, Inc, 2001.

[5] A. B. Hargadon and Y. Douglas, When Innovations Meet Institutions: Edison and the Design of the Electric Light, Administrative Science Quarterly, vol. 46, pp. 476-501, 2001.

[6] Y.Z.Du and Y.L.Zhang, Review on new venture mortality and the possible growth research directions, Science of Science and Management of S.\& T., vol. 30, pp. 136-142, 2009.

[7] N.Xing, Difficulties and Countermeasures of raising venture capital for university entrepreneurs in China, Economic Review, vol. 01, pp. 41-42, 2012.

[8] P. Piperopoulos and D. Dimov, Burst bubbles or build steam? Entrepreneurship education, entrepreneurial self-efficacy, and entrepreneurial intentions, Journal of Small Business Management, vol. 53, pp. 970-985, 2015.

[9] H. Oosterbeek, M. Van Praag and A. Ijsselstein, The impact of entrepreneurship education on entrepreneurship skills and motivation, European economic review, vol. 54, pp. 442-454, 2010.

[10]H. E. Aldrich and C. M. Fiol, Fools rush in? The institutional context of industry creation, The Academy of Management Review, vol. 19, pp. 645-670, 1994.

[11]S.H.Jia, Achievement of College Students' Entrepreneurship Ability: Enlightenment and Reflection on the Practical Investigation of Entrepreneurs in Yiwu, Zhejiang Province, China Higher Education Research, vol. 07, pp. 74-76, 2008. 